\title{
Affective and Cognitive Outcomes of Project-based Teamwork in a Model Lower Secondary School: The Case of Nuclear Energy
}

\author{
Georgios Tsaparlis ${ }^{1 *}$, Sotirios Hartzavalos², Vasiliki Vlacha ${ }^{3}$, Constantina Malamou ${ }^{3}$, Ioanna Neila ${ }^{3}$, Christina Pantoula ${ }^{3}$ \\ 'Department of Chemistry, University of loannina, Ioannina, Greece, ${ }^{2}$ Kastellanoi Senior High School (Lykeion), Corfu, Greece, ${ }^{3}$ Zosimaia Model \\ Junior High School (Gymnasion), Ioannina, Greece
}

*Corresponding Author: gtseper@cc.uoi.gr

\section{ABSTRACT}

We report on our experience with the implementation of project-based teamwork on nuclear energy with 14 ninth-grade students from a lower secondary model school and its assessment using two written questionnaires, which were answered by the students after the completion of the project. The first questionnaire elicited students' opinions about the overall project, while the second questionnaire examined students' acquired knowledge. All the students were satisfied with their experience. The preparation and organization of the team members, their collaboration and discussions, and the presentation at a public seminar were considered the most important stages of the project. In addition, the preparation and organization, the practice in public presentation, the motivation for learning, and critical thinking were important skills and competencies developed. Students benefited from their familiarity with searching and evaluating information and were positive about their contact with scientists. With regard to the knowledge acquired, positive results emerged for the model school students as compared to beginning $1^{\text {st }}$-year university students from a previous study. The results highlight the importance of project-based work with model school students, as well as the role of the interaction between schools, society, and research institutions.

KEY WORDS: model schools; project type work; context-based science; teamwork; nuclear energy

\section{INTRODUCTION}

\section{The Problems with Teaching and Learning about Nuclear Energy}

S cientific literacy is generally accepted and valued by science educators as a targeted learning outcome of general education. According to the international research project Program for International Student Assessment (PISA) of the Organization for Economic Cooperation and Development (OECD), scientific literacy is defined as:

The ability to engage with science-related issues and with the ideas of science, as a reflective citizen. A scientifically literate person, therefore, is willing to engage in reasoned discourse about science and technology which requires the competencies to: (1) Explain phenomena scientifically (recognize, offer, and evaluate explanations for a range of natural and technological phenomena), (2) evaluate and design scientific enquiry (describe and appraise scientific investigations and propose ways of addressing questions scientifically), and (3) interpret evidence and data scientifically (analyze and evaluate scientific information, claims, and arguments in a variety of representations and draw appropriate conclusions) (OECD, 2015. p. 4).

As scientific knowledge constitutes $50 \%$ in the PISA framework for testing scientific literacy, scientific knowledge is essential for participating in a relevant social discussion and in decision making about crucial problems, such as whether a nuclear fusion plant should be built.

Formal education often neglects a range of science topics relevant to health and medicine, nutrition, environment, energy, new materials, and astronomy and space. Such topics are more likely to be encountered only in informal forms and settings of learning. However, such knowledge can shape a citizen's attitudes toward science and scientific problems (for example, Halkia, 2003; Halkia et al., 2001; Jenkins, 1999; Wellington, 1991). Nuclear science and nuclear energy are important and relevant branches of knowledge. It is well known that nuclear science has two kinds of uses and applications, which are important in world politics and to society: (i) Peaceful ones, such as medical applications and the use of nuclear plants for the production of cheap and "clean" energy; and (ii) military applications related to nuclear weapons. While most people are against nuclear weapons, there are also concerns over the peaceful use of nuclear energy, with many citizens worrying about environmental issues and the danger of nuclear accidents.

Although scientific knowledge about the peaceful and military uses of nuclear energy is considered to be a necessary part of practical and civic scientific literacy for citizens (Shamos, 1995; Tsaparlis et al., 2013), this knowledge and these experiences are not currently offered by schools to students, 
both in Greece and in many other countries (Tsaparlis et al., 2013). The topic of nuclear energy in general education continues to be problematic because of its high conceptual demand (for example, Nakiboghlu and Tekin, 2006; Tsaparlis et al., 2013), and also for historical and systematic reasons; when included in curricula, it is usually placed late in the programs, with the result that it is often excluded altogether.

Numerous education studies have investigated various aspects of nuclear energy and associated concepts and topics. We refer below to some of these studies. The public in general has been reported to have only a partial and confused understanding of radioactivity (Durant et al., 1989; Lucas, 1987) as well as in connection with nuclear accidents, such as those of Chernobyl or the Goiania accident in Brazil (Cross et al., 1996; Eijkelhof and Millar, 1998; Martins, 1992; Nunes and Zylbersztain, 1990). More importantly for this study, the attitudes of high school students' toward nuclear power plants have been examined by Showers and Shrigley (1995), while Kılınç et al. (2013) have explored students' ideas about the risks and benefits of nuclear power. Others have also examined students' attitudes toward nuclear energy or nuclear radiation (Brown, 2018; Calhoun et al., 1988; Dulski et al., 1995), as well as their understanding of nuclear energy and radioactive waste management (Powell et al., 1994). Students' understanding of radioactivity and radiation has been studied by Kaczmarek et al. (1987), by Eijkelhof et al. (1990), and by Boyes and Stanisstreet (1994). Millar (1994) focused on the lack of differentiation of the terms "radioactive-source" and "radiation." Yang and Anderson (2003) investigated senior high school students' preference and reasoning modes about the uses of nuclear energy.

In this paper, we report on the implementation of a projectbased group learning activity about nuclear energy with 14 ninth-grade students of the Zosimaia Model Junior High School in Ioannina, Greece (henceforth to be referred to simply as "Zosimaia School"), and on the assessment of this work with two written questionnaires, administered to the students after the completion of the overall project. The first questionnaire elicited students' opinions about the project, while the second questionnaire examined students' acquired relevant knowledge. The topic of nuclear energy was chosen on the $30^{\text {th }}$ anniversary (1986-2016) of the nuclear accident at Chernobyl.

\section{Model Schools in Greece}

Greek education specialists, politicians, and the wider society have been occupied over recent years with model schools, those schools in which student selection is through examinations. Consequently, "very good" students are selected for model schools. In addition, in both model and experimental schools (schools in which student selection is made by lottery), the teachers have high subject-specific or education-based qualifications (e.g., masters' and/or doctorate degrees) while they were selected and placed in schools after proper evaluation. It is not then surprising that these schools are characterized by the production of high-quality educational work and the promotion of educational innovation. Note that traditionally in Greece the so-called "good students" often have very high performance both in (a) language and literature and (b) science and mathematics courses, and at the same time, these students exhibit an inclination to and preference for science-related higher studies and professions (e.g., medical doctors, engineers, and scientists).

One feature of the model and experimental schools is the practice of students carrying out extra educational work with the formation of working groups that operate after the end of the normal school schedule. Each working group is occupied with a specific knowledge sector, with the aim to promote innovation as well as to develop in students particular abilities and inclinations. Participation in a working group is optional and related to students' interest in a particular knowledge sector. The ultimate aim of having students work in working groups is (under the guidance and supervision of their school teachers) to use modern educational methods and actions in the model school (such as carrying out project-based teamwork, collaborating with scientists, and presenting to the general public of their findings and conclusions), in the belief that these can help students to acquire useful knowledge, change modes of thinking and attitudes, and can be effective in helping them contribute to the communication to society of scientific progress, and possibly become themselves innovative future scientists.

In the study, which is reported here, from 88 students in the ninth grade of the Zosimaia School in the 2015-16 school year, 14 students participated, who belonged to the "Physical Sciences and Technology working group." The topic of study was nuclear energy. This topic is actually included in the lower secondary Greek school program of the ninth-grade physics course, being the last of four major units, entitled "Nuclear phenomena - the nucleus" and consisting of two chapters $\left(10^{\text {th }}\right.$ : The atomic nucleus and $11^{\text {th }}$ : Nuclear reactions). The content covered is adequate and satisfactory but, unfortunately, this unit is often excluded from the teaching schedule and not taught. In upper secondary school, "Nuclear chemistry" is the last (the $5^{\text {th }}$ ) chapter in the tenth-grade chemistry course, but again it is generally neglected. Therefore, secondary school graduates in Greece have a general lack of knowledge about nuclear science, its uses, and abuses.

The students in the present study had the opportunity to listen and discuss with distinguished scientists working in a university laboratory and research institutes (see below), and in this way to study and present their conclusions at a public event in the city of Ioannina, transmitting to local people the message that they must trust scientifically substantiated views and not become victims of misinformation. In this paper, we report about the implementation and assessment of projectbased teamwork about nuclear energy with the 14 ninth-grade students of the Zosimaia School.

\section{Project-based Teamwork in Education}

Project-based learning (PBL) is an instructional method in which students explore current real-world problems, with 
the aim to gain deep knowledge and understanding. It first appeared in 1969 as a new approach in medical education at McMaster University in Canada. The following are core features that characterize PBL (Barrows, 1996): (1) It is student-centered; (2) it involves small peer-groups; (3) teachers act as facilitators; (4) problems are the focus and stimulus for learning; (5) it develops problem-solving skills; and, (6) new knowledge is acquired through self-directed learning. It is a type of inquiry-based learning, where the context of learning is provided through authentic questions and problems within real-world practices (Al-Balushi and Al-Aamri, 2014). Blumenfeld et al. (2000) described project-based science as a process in which "students ... construct knowledge by solving real problems through asking and refining questions, designing and conducting investigations, gathering, analyzing, and interpreting information and data, drawing conclusions, and reporting findings" (p. 150). Summing up, PBL is based on three constructivist principles: (1) Learning is context-specific, (2) learners are involved actively in the learning process, and (3) they achieve their goals through social interactions and the sharing of knowledge and understanding (Cocco, 2006).

PBL is student-centered, and therefore contrary to old teachercentered instructional models and methodologies that require, encourage, and reward students for learning facts passively and being able to recite them out of context in a short-term. Such models are inadequate for preparing students to live in the modern world of fast and vast information and communication, while, in PBL, students exploit the digital world and produce high quality, collaborative products (Markham, 2011). It should be noted that the definition and understanding of PBL are varied in the literature, with other terms, such as taskbased learning, case-based learning, context-based learning, and problem-based learning being also used. Some of these alternatives (task-based learning and context-based learning) are quite relevant to the implementation of our approach. For a recent literature review of PBL, see Kokotsaki et al. (2016).

The roots of PBL can be traced back to John Dewey, who, in his "pedagogic creed" (published in 1897), advanced the idea of learning by doing, believing in the so-called expressive or constructive activities:

The teacher is not in the school to impose certain ideas or to form certain habits in the child but is there as a member of the community to select the influences which shall affect the child and to assist him in properly responding to these (Dewey, 2006. p. 25).

The following are the essential project design elements in PBL (Larmer et al., 2015): (1) Key knowledge, understanding, and success skills; (2) challenging problem or question; (3) sustained inquiry; (4) authenticity; (5) student voice and choice; (6) reflection; (7) critique and revision; and (8) public product. Of special importance and relevance to this work is the element of the public product, according to which students make their project work public by presenting/displaying and explaining their product to people beyond the classroom.
While PBL work can be assigned to individual students, it is customary in practice to adopt a team learning process, in which the whole team participates actively in a regulatory and decisive way (Frey, 1982). Teamwork is a form of cooperative learning, with the main feature that students work together in small groups to accomplish shared learning goals, such as to arrive at the solution of a given task. As an instructional procedure, cooperative learning is central to the theories of a wide range of social sciences, such as anthropology, political science, sociology, and psychology (Johnson and Johnson, 1991). In our case, the emphasis was placed on teamwork with learner-centered features: Students formulate the questions they would like to be answered about the topic, and determine, in consultation with and the advice of the teacher, the objectives and the desired product. Important also is considered to be the cooperation with out-of-school institutions relevant to the topic of inquiry, as well as the informing of the parents of the participating students about the project and the dissemination to society through the school of the achievements of science. Science courses are particularly suitable for the implementation of such project work.

An integral part of project-based work is its formative and summative assessment, with which an evaluation is made of how the knowledge and experience acquired have shaped new values and behaviors of students (and teachers). In fact, this constitutes the essence of true learning. According to Frey (1982), even if the stated objectives are not completely achieved, a great educational value should be attached to both the quality of actions and the team effort.

There have been many studies that used PBL in general science (e.g., Kin and Day, 2009; Pease and Kuhn, 2011) and the various science disciplines: Physics (e.g., Szott, 2014), chemistry (e.g., Dakabesi et al., 2019; Hicks and Bevsek, 2011; Overton and Randles, 2015), and biology (e.g., Kendler and Grove, 2004).

\section{Study Aims}

Two types of outcomes of this project-based teamwork were the aims of the present study: (a) Affective outcomes and (b) cognitive outcomes.

Regarding the affective outcomes, several sub-questions arose, such as:

i. Were the students happy with their project work?

ii. What were their opinion about the importance of the various stages of project work, the difficulties encountered by them, and the skills and competencies cultivated by project work?

iii. What were the students' views and disposition about teamwork?

iv. Did the students' overall experience from the project change their image of science?

Turning to the cognitive outcomes, we targeted at measuring the achievement of the students in questions about nuclear science. In this respect, the availability of a previous study 
which tested the knowledge about nuclear science of beginning $1^{\text {st }}$-year university physics and primary education students' knowledge about nuclear science, prompted us to use with the model school students of our study a major part of the knowledge questionnaire that had been used in this previous study with the model school students.

\section{METHODOLOGY}

\section{Research Design}

The study has the features of a case study, in which "the researcher typically observes the characteristics of an individual unit - a child, a clique, a class or a community," and the purpose is "to probe deeply and to analyze intensively the multifarious phenomena that constitute the life cycle of the unit with a view to establishing generalizations about the wider population to which that unit belongs" (Cohen et al., 2007. p. 258). It is evident that the "case" is the subject of study and its context.

We also emphasize that the study is an ex post facto (afterthe-fact) research, that is, we thought and decided to carry out the assessment (the measurements) after the whole project was organized and executed without interference from the main researcher (Salkind, 2010). Of necessity, this has posed apparent restrictions and limitations on the completeness of the study.

Figure 1 provides a schematic diagram of the methodology of the project.

Research Environment, Participants, and Sampling Design On the $30^{\text {th }}$ anniversary of the nuclear accident at Chernobyl, the Zosimaia School undertook to organize a public seminar, which led to the project to which we refer to in this work. This project was carried out by 14 ninth-grade students (ten boys and four girls, aged 14-15 years old) of the school, under the supervision of four of their teachers, with specialization in mathematics, chemistry, biology, and physics, respectively. The results of the project were presented to the public in a seminar entitled "Nuclear energy: Exploring myths and realities," which was held on May 11, 2016, in the lecture theatre of the Central Library of the University of Ioannina. The seminar was held in cooperation with the Union of Teachers of such Greek schools and the "Democritus" National Research Center (NRC) (education office). The audience consisted of school students, parents of students, university professors, and secondary school teachers, school advisors, and ordinary citizens.

In a first meeting, the four teachers jointly selected the students from the "Physical Sciences and Technology" working group, who, according to the school performance records and the teachers' experience, had a liking for science and mathematics and a high performance in the school science subjects. Fourteen students were selected. It is noteworthy that in their answers to the opinion questionnaire, 12 of the students stated that they liked most the science and mathematics courses, one student preferred the literary subjects (language, history, and literature), and one student preferred history and biology.

\section{Ethical Considerations}

For the participation of the students in the assessment of the project, we followed all the rules of good ethical conduct for implementing a social research study with school students (Taber, 2014). First, we received approval from the "Scientific Supervisory Board" of the school (which includes the school director). In addition, the four teachers informed the parents of the students about the research character and content of the assessment, with a personal letter sent to them through their children. The parents of all the students who took part in the implementation of the project gave their written consent for the participation of their children in the assessment.

Table 1 gives the results of the achievement of these students in their school subjects of mathematics, physics, chemistry, and biology, as well as their final overall grade for the ninthgrade for the 2015-2016 school year. Note that the students' grading, including the end-of-year final examination, was the result of internal assessment by the school, but it is generally accepted that these schools have higher than average standards of student assessment, and taking also into account that the students had been selected to study in this school by means of a rigorous test, supports our claim that these students were high attaining. We note a high achievement both in all four courses and the final grade, thus confirming the statement we made in the introduction that model schools select "very good" students.

\section{Research Procedure}

\section{Description of the project}

At a meeting between the four teachers and the fourteen students, a discussion about the aims of the project and the selection of topics on which students would work was made. The selection was from a range of topics that had been proposed by the "Democritus" NRC of Greece, and six topics were selected, which are shown in Table 2. At the same meeting, the student teams were determined. The procedure was a linear one, that is, a topic was selected first by one student and a partner expressed then his/her interest to collaborate. No complication arose in the implementation of this process. As the students came from the same class, they knew each other before the project, so their mutual acquaintance and friendships must have been a determining factor in team formation. Six teams were formed, of which four consisted of two students each and two groups consisted each of three students.

For each topic, one teacher was supervisor, according to specialization and knowledge of the topic so that to be able to guide properly the students by providing advice and the relevant literature, and by supplying the students with lists of both print books and internet addresses. Meetings of each team with the supervising teacher followed (in school, during various breaks, and at the end of the daily school schedule). In addition, contacts between the teachers and the students through e-mails were available, as well as a distribution of files through Google Drive. 


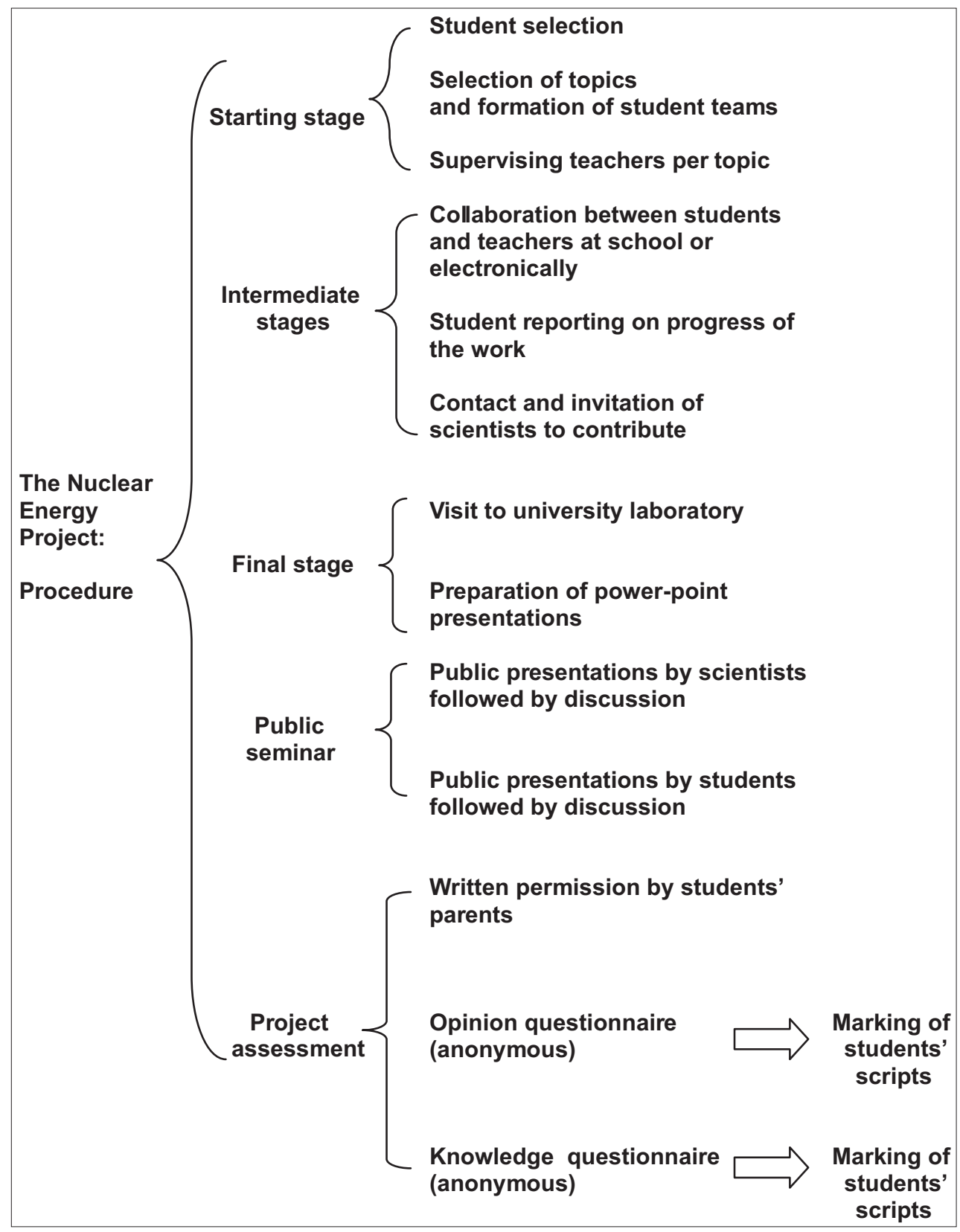

Figure 1: A schematic diagram of the methodology of the project

At this point, the teachers thought to ask for scientific assistance from the local university, and so the collaboration with a professor at the department of medicine arose. The professor suggested that the students with their teachers should make a visit to the university laboratory of medical physics. Students accepted the proposal with great enthusiasm. The students visited the university laboratory after completing their project work, to be better prepared to ask questions and to understand better the issues involved.

In subsequent meetings, in the presence of all 14 students and the four teachers, the students of each team reported on the progress of their work. In addition, relevant issues were discussed and improvements to their work were made. In the final stage, the teams prepared their power-point presentations, which were trialed before all participating students and the teachers provided advice for correcting and improving the presentations.

Another consequence of our cooperation with the Union of Teachers of Model Schools and the NRC was the proposal to invite to the public seminar a researcher from the European Center for Nuclear Research CERN, and another scientist from the Laboratory of Environmental Radioactivity of NRC.

\section{Project Assessment}

The final assessment of the project was made by the response of the students in two written questionnaires: One (first) opinion questionnaire and a (second) questionnaire on knowledge of nuclear science and nuclear energy. Students' answers were anonymous. 
Because the actual questionnaires and students' responses were in the Greek language, for the accuracy of translation into English, we applied Brislin's method of back translation (Brislin, 1970; 1986). The English versions were translated back into Greek by the first author, and the two versions (original and the backtranslated one) were then compared and, after some changes to the English version, the agreement was judged satisfactory.

\section{Research instruments and data analysis}

The first questionnaire (opinion questionnaire): The first questionnaire was based on a questionnaire, which had been used previously in a study about a university laboratory course (Tsaparlis and Gorezi, 2007). Questions were Likert type, with some asking students to justify their choices or express their personal opinion. The questionnaire was presented to the four teachers, who agreed with its content and made various suggestions for corrections and improvements, which led to the final form. The opinion questionnaire consisted of four parts and is described briefly in Table 3.

The analysis of the questionnaire responses was done separately by two of the authors (Tsaparlis and Vlacha), who, after many collaborations and extensive discussions, finally agreed about both the numerical data and the grouping/categorization of the open responses.

The first (opinion) questionnaire consisted of four parts. The first part contained six general questions on the following issues: Which of their courses students liked most, literary courses or science and mathematics; the features and usefulness of the science courses; and the experimental teaching of the

\begin{tabular}{|c|c|c|c|c|c|}
\hline Descriptors & Maths & Physics & Chemistry & Biology & $\begin{array}{c}\text { Final overall } \\
\text { mark }\end{array}$ \\
\hline Mean & 95.0 & 93.0 & 94.5 & 98.0 & 95.3 \\
\hline SD & 4.65 & 6.95 & 6.10 & 3.05 & 2.83 \\
\hline Max. & 100 & 100 & 100 & 100 & 100 \\
\hline Min. & 85 & 80 & 85 & 90 & 91.2 \\
\hline Median & 95 & 95 & 95 & 100 & 94.2 \\
\hline
\end{tabular}

*The marks given for the four subjects are the end-of-year total marks. For each course, these are the result of averaging the whole-year formative assessment mark and the end-of-year mark in the final written examination. The final overall mark is for all contributing courses for the ninth-grade

\begin{tabular}{ll}
\hline Table 2: The titles of the six projects* \\
\hline $\begin{array}{ll}\text { \#1 Nuclear fission and nuclear } & \begin{array}{l}\text { \#4 Effects of radioactivity on } \\
\text { human body - health problems and } \\
\text { fusion }\end{array} \\
\begin{array}{l}\text { \#2 Nuclear fission reactors - } \\
\text { electric power production }\end{array} & \begin{array}{l}\text { little of radioactivity might be good } \\
\text { for health }\end{array} \\
\begin{array}{l}\text { \#3 Radioactive damage under } \\
\text { conditions of actual operation }\end{array} & \text { \#6 Nuclear accidents } \\
\text { *The numbering is according to order of presentation at the public seminar }\end{array}$
\end{tabular}

science courses. The second part also contained six questions about teamwork. The third part consisted of seven questions about the students' projects (e.g., if they were happy with their project, which of the projects of their classmates they liked most and why), and about the skills and competencies cultivated by their project work. Finally, the fourth part had two final questions about the student's overall impression of the project and whether their experience from the project changed their image of science.

The second questionnaire (knowledge questionnaire): The second questionnaire derived from a previous study with university students at the very beginning of their university studies (Tsaparlis et al., 2013). This study will be henceforth referred to as "the previous study," and the students of that study as "the university students," while the students of the current study will be referred to as "the model school students." Table 4 contains examples of questions from the second questionnaire, which consisted of 34 questions. Before the questions, there are some statements (in italics and in quotation marks), which have been taken from articles published in large, national newspapers of Athens (see the previous study). Many questions tested only relevant scientific knowledge, for example, questions 1 and 2 in Table 4. Several dealt with societal issues which, in our opinion, relate to, and attempt to promote students' civic scientific literacy, referring to peace and sustainable development; examples: Questions 5, 6, and 7 in Table 4.

For the assessment of the 14 model school students' knowledge about nuclear science and nuclear energy of the current study, we compared it with the achievement in the same questions of a sample $(n=189)$ of beginning $1^{\text {st }}$-year university students that were reported in the previous study. The subjects of that study were $851^{\text {st }}$-year undergraduate physics students and $1041^{\text {st }}$-year undergraduate primary education students (age of

\section{Table 3: Short description of the first questionnaire (an opinion questionnaire)}

\begin{tabular}{ll}
\hline Part I (general & $\begin{array}{l}\text { Which of their courses did students like most, } \\
\text { questions) }\end{array}$ \\
language, and literature courses or science and \\
mathematics ones? \\
Which are the features and usefulness of the science \\
courses? \\
Students' opinions about the experimental teaching of \\
the science courses \\
Questions about teamwork \\
Questions \\
Part II \\
a. About the students' projects: Were they happy with \\
their project?/Which of the classmates'projects did \\
they like most and why?/Which were their opinions \\
about the importance of the different stages of a \\
project?/Which were their views on the difficulties \\
encountered in the project work? \\
b. About the skills and competencies cultivated by \\
their project work \\
Student's overall impression from the execution of the \\
project \\
Had their experience from the project changed their \\
image of science?
\end{tabular}




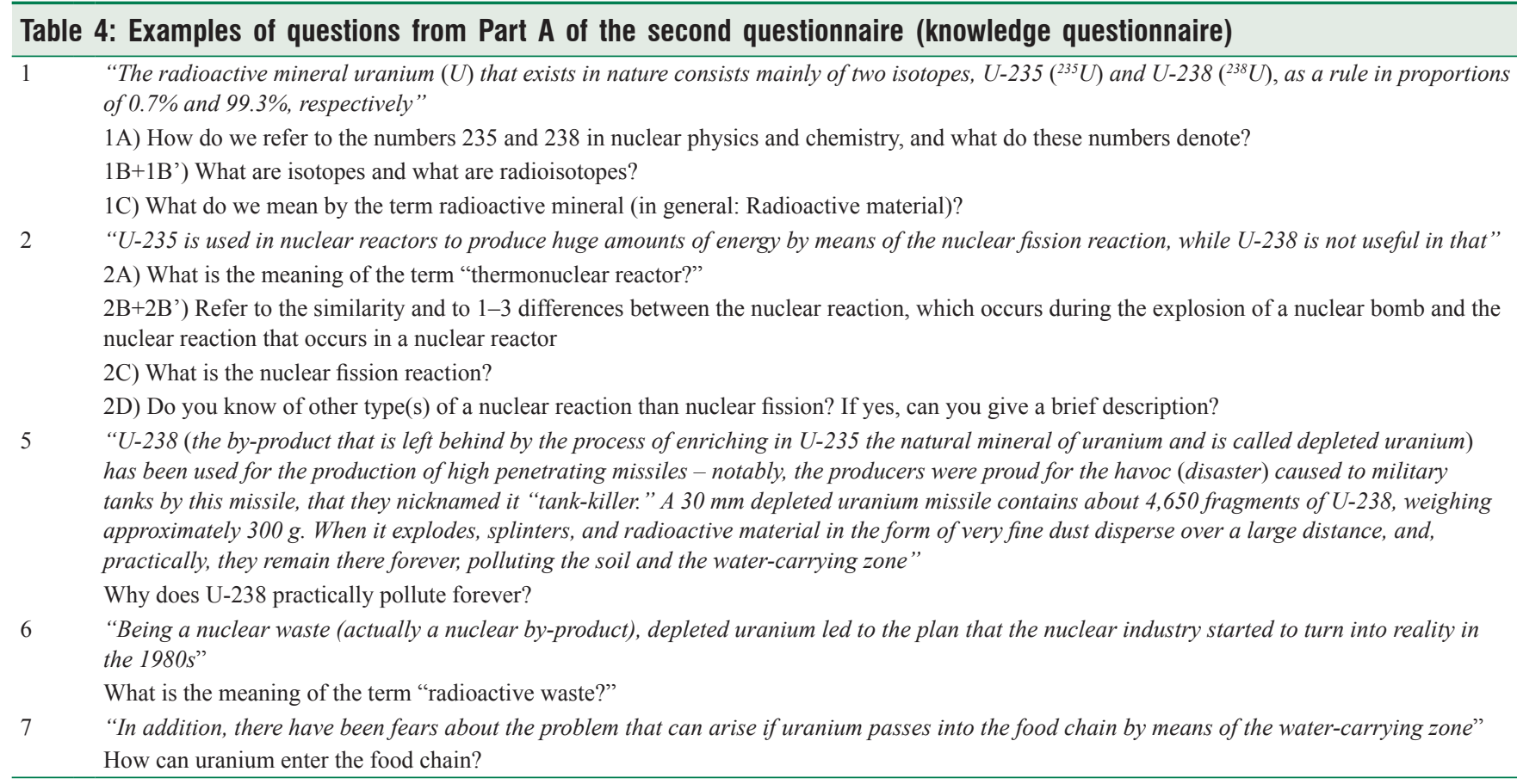

\section{Table 5: The topics/titles of the presentations and projects* and model school students' preference for them}

\section{Topic and number of preferences Reason/reasons for the} preference

The recent acquaintance with radioactivity in the university laboratory: 1

\#1 Nuclear fission and nuclear fusion: $9^{* *}$

\#2 Nuclear fission reactors electric power production: 5

\#3 Radioactive damage under conditions of actual operation: 1 \#4 Effects of radioactivity on human body - Health problems and protection: 3

\#5 Is radioactivity always harmful? A little of radioactivity might be good for health: 3

\#6 Nuclear accidents: 1

Good presentation

*The ordering is according to the order of presentation at the seminar. **Four students selected project \#1 as their only choice

18-19 years) (Tsaparlis et al., 2013). Note that, we considered it inappropriate to attempt a comparison of our student sample's knowledge about nuclear science with an apparently equivalent (in terms of school type, grade, and student ability) control group of students, because the topic of nuclear energy is outside the curriculum for students of such young age.
The students' answers to the knowledge questionnaire were evaluated by one of the authors (Hartzavalos), who also evaluated the answers in the previous study. For each answer, a total mark was calculated by assigning five points to each acceptable answer, three points to each partially acceptable answer, one point to each unacceptable answer, and zero points to a non-answer.

\section{RESULTS AND DISCUSSION}

Figure 2 gives a schematic diagram of the outcomes of the project.

\section{Affective Outcomes}

The visit to the university laboratory

Visiting the laboratory of medical physics was an "unforgettable experience" for the students and resulted in an additional presentation, which was about the visit to the university laboratory. The description below is an excerpt from the presentation at the seminar by one student:

The professor introduced us to elementary knowledge about nuclear energy and ionizing radiation. We talked about internal and external irradiation, the different, natural, and anthropogenic radiation sources. Furthermore, we were informed about the amounts of radiation we receive daily. All of us have gained new knowledge about radiation, a concept that for the majority of people hides the threat, and I guess that most of us had considered radiation from a different perspective. After we came in contact with the basic scientific concepts, we were able to experiment ourselves, making measurements and discovering experientially different kinds of radiation. We also came to know the principle of operation of one of the largest in the world (outside North America) radioactivity counters for 


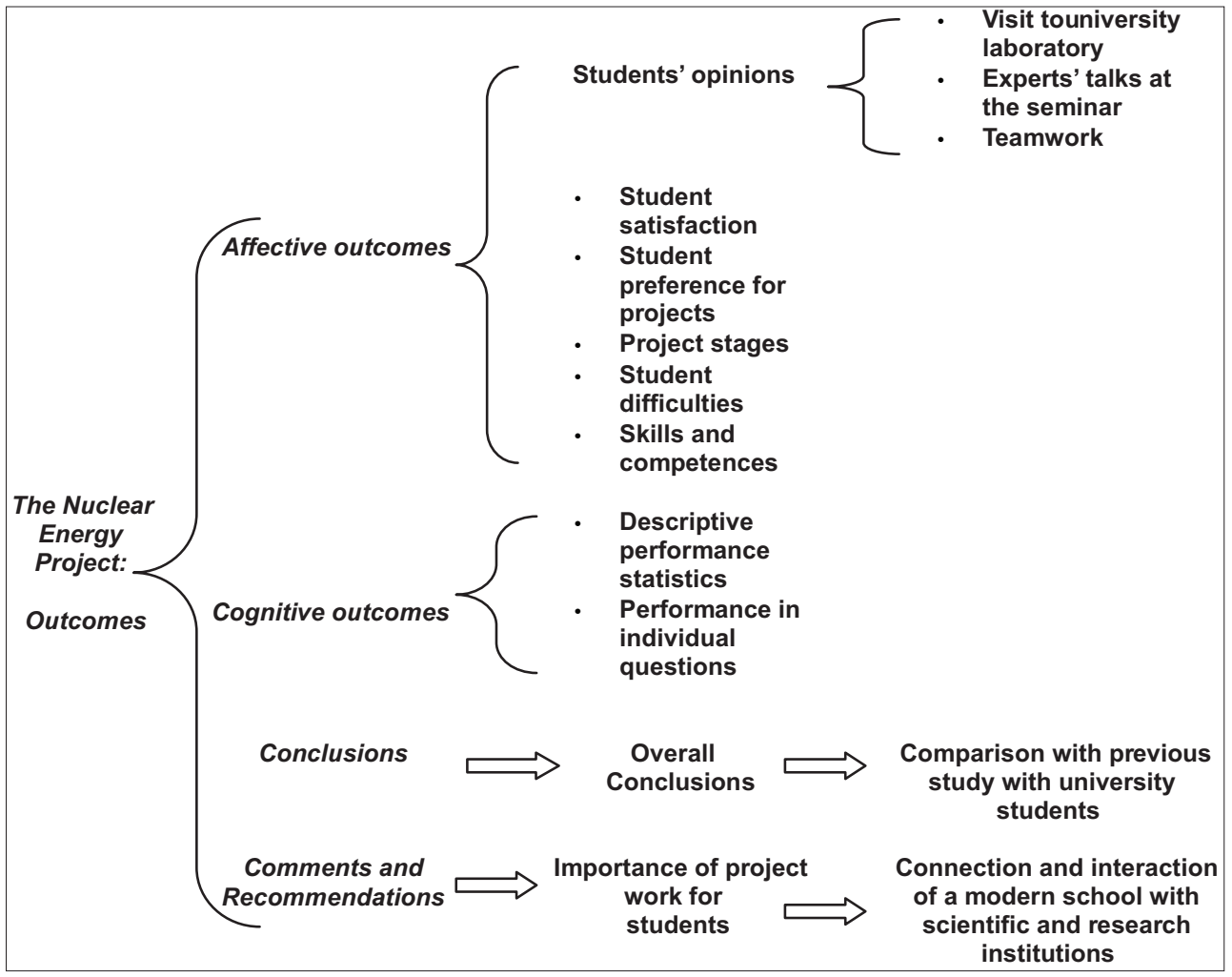

Figure 2: A schematic diagram of the outcomes of the project

the whole human body. This counter was assembled entirely by the professors of the laboratory. A radioactive material detection game particularly pleased us, (and) we also carried out measurements at different places in the courtyard of the laboratory.

Almost all students (13, of which six very much and six much) found useful their familiarization with radioactivity in the university laboratory.

\section{The presentation of the projects in the seminar}

All presentations were made in PowerPoint prepared by students and all had, in the end, added the literature. As expected, the quality of the presentations was varied and certainly some presentations were better than others, both in terms of the content and in terms of the presentation per se.

\section{Students' comments on the experts' talks}

Eleven students judged positively the talks at the seminar by the three scientific experts. Two students had a neutral disposition and one student a rather negative view about these talks.

\section{Teamwork}

Except for one student, who expressed a negative opinion, everyone else was positive about teamwork: Nine students found it very useful and effective and four others adequately so.

\section{Student satisfaction with their projects}

Students were asked to state whether they were happy with their particular project work. Eleven students were very satisfied, and the other three rather satisfied. Eight students were satisfied with the result, four with their learning, and two for their good presentation. On the other hand, one student (with a preference for literature courses) noted: "It was not what I had expected."

\section{Preference for the various projects}

Students were asked to state which of the remaining projects (apart from their own one) they liked most (they could select up to two from the six projects). Table 5 shows the titles of the six projects and the six plus one presentation and the results in terms of preferences. The project about nuclear fission and nuclear fusion collected by far the most preferences, followed by the topic of nuclear fission reactors and power generation. Learning new things were often cited as the reason, while it is remarkable that many students used the criterion of a good presentation. It was also important that they had learned things they did not know or did not know well "I learned things that I did not know well" and "I always wondered how to generate energy from uranium."

\section{Importance of the different stages of the projects}

The students were asked to mark the degree of importance of the various stages in project work. Table 6 shows the results. Most important was considered to be the preparation and organization of the team members, the collaboration and discussions with the partner, and the presentation at the seminar, while as less significant was judged the acquaintance with radioactivity in the university laboratory, and the writing of a scientific text. The 
low placement of the importance of the visit to the university laboratory is in principle in contrast to the positive to the very positive opinion expressed by the students (see above). It is of interest to note that Henriksen and Jorde (2001) developed an exhibition on radiation-related environmental issues, which provided learning outcomes in the understanding of radiation for the majority of the 16-year-olds Norwegian students; however, students who had strong alternative conceptions about the exhibition's issues found it difficult to interpret correctly new concepts introduced at the exhibition. Two later relevant studies with very large samples of students (Dimopoulos and Koulaidis, 2006; Neresini et al., 2009) provided positive affective but problematic cognitive outcomes.

\section{Students' difficulties encountered in the project work}

Table 7 shows the results. We observe that all relevant issues presented very little difficulty to the students, with easier being the study of foreign literature, while the presentation in the seminar was judged as most demanding.

\section{Development of skills and competencies}

Table 8 shows the results for the contribution of the project work to the development of various skills and competencies in the 14 model school students. The preparation, organization,

\begin{tabular}{|c|c|c|c|}
\hline \# & Project stage & Mean value & Median \\
\hline 1 & $\begin{array}{l}\text { Preparation and organization by the } \\
\text { team members }\end{array}$ & 3.57 & 4 \\
\hline 2 & $\begin{array}{l}\text { Collaboration and discussions with } \\
\text { teammate }\end{array}$ & 3.50 & 3.5 \\
\hline 3 & Presentation at the seminar & 3.43 & 3.5 \\
\hline 4 & Personal relevant study & 3.23 & 3 \\
\hline 5 & $\begin{array}{l}\text { Preparation of PowerPoint } \\
\text { presentation }\end{array}$ & 3.21 & 3 \\
\hline 6 & Instruction by our teachers & 3.00 & 3 \\
\hline 7 & $\begin{array}{l}\text { Search for relevant supporting } \\
\text { literature }\end{array}$ & 2.93 & 3 \\
\hline 8 & Guidance by our teachers & 2.79 & 3 \\
\hline 9 & $\begin{array}{l}\text { Learning about radioactivity in the } \\
\text { university laboratory }\end{array}$ & 2.57 & 3 \\
\hline 10 & Writing up of a scientific text & 2.43 & 2.5 \\
\hline
\end{tabular}

Table 7: Model school students' views on the difficulties encountered in the project work*

\begin{tabular}{llcc}
\hline \# & Encountered difficulties & Mean value & Median \\
\hline 1 & Presentation & 1.21 & 1 \\
2a & Supporting literature in mother tongue & 1.14 & 1 \\
2b & Understanding of basic theoretical & 1.14 & 1 \\
& principles & & \\
4 & Collaboration with team mate & 1.00 & 1 \\
5 & Supporting literature in English & 0.93 & 1 \\
\hline *Mean and median values in a 0-4 scale: $0:$ No difficulty; 4: Many \\
difficulties
\end{tabular}

and practice in a public presentation (to peers and the public) were assumed as most important; then followed the motivation for learning and critical thinking.

\section{Other findings}

All 14 students expressed a positive impression and experience from the implementation of the project. Moreover, on the question whether their experience from the project changed

\begin{tabular}{|c|c|c|c|}
\hline \# & Skills and competencies & Mean value & Median \\
\hline 1 & Preparation and organization & 3.29 & 4 \\
\hline 2 & Training on public presentation & 3.21 & 3.5 \\
\hline $3 a$ & Motive for learning & 3.14 & 3 \\
\hline $3 b$ & Critical thinking & 3.14 & 3 \\
\hline 5 & Collaboration & 2.93 & 3 \\
\hline $6 a$ & $\begin{array}{l}\text { Understanding of theory relevant to } \\
\text { my project }\end{array}$ & 2.86 & 3 \\
\hline $6 \mathrm{~b}$ & $\begin{array}{l}\text { Connection of theory with practice } \\
\text { (applications) }\end{array}$ & 2.86 & 3 \\
\hline 8 & Connection of science with life & 2.79 & 3 \\
\hline $9 \mathrm{a}$ & Search for literature sources & 2.71 & 3 \\
\hline $9 b$ & Distribution of available time & 2.71 & 3 \\
\hline $9 \mathrm{c}$ & Writing up of a scientific text & 2.71 & 3 \\
\hline $12 \mathrm{a}$ & Taking of initiatives & 2.57 & 3 \\
\hline $12 b$ & $\begin{array}{l}\text { Connection of new concepts to } \\
\text { existing knowledge }\end{array}$ & 2.57 & 3 \\
\hline 14 & Statement of objectives & 2.43 & 2.5 \\
\hline 15 & Personal self-image & 2.36 & 2.5 \\
\hline 16 & $\begin{array}{l}\text { Familiarization with foreign } \\
\text { (English) literature }\end{array}$ & 2.07 & 2.5 \\
\hline
\end{tabular}

Table 9: Total percentage mean mark for each model school student for the 34 questions

\begin{tabular}{lccccc}
\hline Student \# & Mark & Student \# & Mark & Student \# & Mark \\
\hline 1 & 68.8 & 6 & 57.6 & 11 & 31.8 \\
2 & 8.2 & 7 & 37.0 & 12 & 49.3 \\
3 & 65.2 & 8 & 55.8 & 13 & 78.2 \\
4 & 14.2 & 9 & 21.2 & 14 & 63.0 \\
5 & 84.2 & 10 & 40.6 & & \\
\hline
\end{tabular}

Table 10: Descriptive statistics for the 31 questions in common*

\begin{tabular}{lcc}
\hline Descriptor & $\begin{array}{c}\text { University students } \\
(\mathbf{n = 1 8 9})\end{array}$ & $\begin{array}{c}\text { Model school } \\
\text { students }(\mathbf{n = 1 4 )}\end{array}$ \\
\hline Mean & 27.3 & 50.4 \\
SD & 13.2 & 18.0 \\
Max. & 63.2 & 80.0 \\
Min. & 7.2 & 14.3 \\
Median & 24.7 & 51.4 \\
\hline
\end{tabular}

*All marks are percentage 
their image of the sciences (physics, chemistry, and biology), ten students answered that it made it more positive (six students: Very positive, and four students: Rather positive), while it did not change the disposition of the remaining four students; this might imply that all or some of these four students had already a positive disposition, so the project did not change it to make it more positive.

\section{Cognitive Outcomes}

\section{Descriptive statistics}

Table 9 provides the percentage of marks attained by each of the 14 students for the 34 knowledge questions. (For the marking scheme, see above just before Table 3 ). The average mark for the 14 students for the whole test is 48.2, standard deviation 23.6, maximum mark 84.2, minimum mark 8.2, and median 52.6. It is observed that there was a spreading of marks, that is, the 14 students did not have a similar performance.
Out of the 34 questions of the questionnaire used with the model school students, three questions were new, not included in the questionnaire of the previous study. Table 10 provides the descriptive statistics for the 31 questions in common. The marking derived from the 5-3-1-0 marking scheme described above, which was then transformed to percentage marks by multiplying the average total mark by 20 . The difference of the mean values between the two groups is $50.4-27.3=23.1 \%$, showing the superiority of the model school students. The sample size of 14 is of course typically not acceptable for statistical comparisons, so it is not advisable to attempt such a comparison.

Comparison of performance in the individual questions

Table 11 lists the topics of all 34 questions of the knowledge questionnaire, the corresponding percentage performances for the university and the model school students, and the differences $D$ between the two samples. Questions 3A, 4A, and

Table 11: Percentage performance of the university and model school students according to the marking 5-3-1-0 in the individual questions, and the differences $D$ between the two samples*

\begin{tabular}{|c|c|c|c|c|}
\hline Question \# & Topic of question & University & Model school & Difference $^{\star *} D$ \\
\hline $1 \mathrm{~A}$ & Mass number & 33.9 & 64.3 & 30.4 \\
\hline 1B & Isotopes & 31.2 & 45.7 & 14.5 \\
\hline 1B' & Radioisotopes & 7.2 & 34.3 & 27.1 \\
\hline $1 \mathrm{C}$ & Radioactive mineral (in general, radioactive material) & 19.4 & 51.4 & 32.0 \\
\hline $2 \mathrm{~A}$ & Nuclear reactor & 41.0 & 78.6 & 37.6 \\
\hline 2B & Similarities between nuclear bomb and nuclear reactor & 26.9 & 68.6 & 41.7 \\
\hline $2 \mathrm{~B}^{\prime}$ & Differences between nuclear bomb and nuclear reactor & 31.2 & 58.6 & 27.4 \\
\hline $2 \mathrm{C}$ & Nuclear fission reaction & 28.2 & 80.0 & 51.8 \\
\hline $2 \mathrm{D}$ & Other than fission type of nuclear reaction & 20.6 & 72.9 & 52.3 \\
\hline $3 \mathrm{~A}$ & Half-life time & 22.1 & 64.3 & 42.2 \\
\hline $3 \mathrm{~B}$ & U-238 (and also U-235) out of the human body & N/A & 37.1 & N/A \\
\hline $4 \mathrm{~A}$ & Meaning of chemical toxicity & $\mathrm{N} / \mathrm{A}$ & 21.4 & N/A \\
\hline $4 \mathrm{~B}$ & Chemical toxicity of uranium isotopes & N/A & 20.0 & N/A \\
\hline 5 & U-238 (depleted uranium) pollutes for ever & 40.6 & 65.7 & 25.1 \\
\hline 6 & Nuclear waste & 43.0 & 57.1 & 14.1 \\
\hline 7 & Uranium in food chain & 51.4 & 70.0 & 18.6 \\
\hline 8 & Thermonuclear reactor & 63.2 & 37.1 & -26.1 \\
\hline 9A & Equation for the hydrogen fusion reaction & 13.8 & 14.3 & 0.5 \\
\hline 9B & $E=m c^{2}$ & 14.7 & 14.3 & -0.4 \\
\hline $9 \mathrm{C}$ & Nuclear fusion in sun & 27.0 & 52.9 & 25.9 \\
\hline $10 \mathrm{~A}$ & Ionization of hydrogen & 39.8 & 47.1 & 7.3 \\
\hline 10B & Origin of protons and electrons of plasma & 33.2 & 28.6 & -4.6 \\
\hline $11 \mathrm{~A}$ & Advantages of nuclear energy projects over conventional fuels & 23.8 & 75.7 & 51.9 \\
\hline 11B & Production of hydrogen by electrolysis of water & 25.2 & 57.1 & 31.9 \\
\hline $11 \mathrm{C}$ & Energy for electrolysis & 14.0 & 37.1 & 23.1 \\
\hline $12 \mathrm{~A}$ & Nuclear radiation/radioactivity & 19.0 & 25.7 & 6.7 \\
\hline $12 \mathrm{~B}$ & Natural radioactivity & 22.9 & 58.6 & 35.7 \\
\hline $13 \mathrm{~A}$ & Alpha particles & 15.1 & 47.1 & 32.0 \\
\hline 13B & Gamma radiation & 13.2 & 34.3 & 21.1 \\
\hline $13 \mathrm{C}$ & $\mathrm{X}$-rays & 18.1 & 31.4 & 13.3 \\
\hline $13 \mathrm{D}$ & Other type of radioactive radiation & 10.1 & 44.3 & 34.2 \\
\hline 14 & Radioactivity affects human and animal health & 50.7 & 60.0 & 9.3 \\
\hline 15 & Medical diagnostic and therapeutic applications of nuclear physics & 22.1 & 51.4 & 29.3 \\
\hline 16 & Radiation limits for nuclear workers and for the general population & 24.7 & 34.3 & 9.6 \\
\hline
\end{tabular}

*N/A: Not applicable. ${ }^{* *} D=$ (Model school)-(University) 
4B given to the model school students were new, that is, they did not occur in the case of the university students.

The questions with the highest performances $(\geq 70 \%)$ of the model school students were the following: $2 \mathrm{C}$ (about the "nuclear fission reaction," 80\%), 2A ("nuclear reactors," $78.6 \%$ ), 11A ("advantages of nuclear energy projects over conventional fuels," 75.7\%), 2D ("other than fission type of nuclear reaction," 72.9\%), and 7 ("uranium in food chain," $70.0 \%$ ). It is notable that the first three of the above questions dealt with matters directly related to the nuclear energy and that the relevant students" projects \#2 on "nuclear fission and nuclear fusion" and \#3 on "nuclear fission reactors and power generation" collected the most preferences among the fourteen students (Table 5). On the other hand, the lowest performances $(<30 \%)$ of the model schools students were noted in questions 9A ("equation for the hydrogen fusion reaction" $14.3 \%$ ), 9B ("equation $E=m c^{2}, " 14.3 \%$ ), 4B ("chemical toxicity of uranium isotopes," $20.0 \%$ ), 4A ("meaning of chemical toxicity," 21.4\%), 12A ("nuclear radiation/radioactivity," $25.7 \%$ ), and $10 \mathrm{~B}$ ("origin of protons and electrons of plasma," $28.6 \%$ ). In question $4 \mathrm{~A}$, the issue of toxicity (which did not enter the university study) was very difficult. Apparently the students were not aware of this term and possibly associated this with something "bad."

Questions 9A and 9B had a very small difference $|D|<1$. These questions were of mathematical nature: $9 \mathrm{~A}$ asked for the equation for the nuclear reaction that describes the fusion of hydrogen, while 9B asked the explanation in physics terms (through the famous energy-mass equation $E=m c^{2}$ ) for the huge amount of energy that is released in nuclear reactions.

\section{CONCLUSIONS}

All the students were satisfied with their experience. The preparation and organization of the team members, their collaboration and discussions, and the presentation at a seminar were considered the most important stages, while the practice in public presentation, the motivation for learning, and critical thinking were important skills and competencies developed. The majority of the students declared that they benefited from their familiarity with searching and evaluating information, expressed a favorable opinion with regard to their acquaintance with radioactivity in the university laboratory, were enthusiastic about their contact with scientists, and developed a more positive image of science. Almost all students were positive about teamwork and expressed a favorable opinion about their acquaintance with radioactivity in the university laboratory and the talks by the three scientists at the seminar.

One issue that should be recognized is the need to encourage students to participate more actively in questioning the experts during the seminar. In the present study, questions and the discussion tended to be monopolized by the adult audience. This was not all bad for the students, as they were given the chance to see how scientific debates are carried out.
With regard to the knowledge acquired, in general, very positive results emerged compared to results for beginning $1^{\text {st }}$-year university students from a previous study (Tsaparlis et al., 2013). The mean value of the performance for the model school students was $50.41 \%$ (s.d. 18.92), while for the university students, the corresponding figures were 27.33 (s.d. 13.19). It must be noted that (as followed from a second part of the knowledge questionnaire) 11 out of the 14 students declared that they knew nothing or had just heard about the topics of the questions, while 13 of the students stated that the questions were relevant to their project and/or the project(s) of the other students.

\section{FINAL COMMENTS AND RECOMMENDATIONS}

Science education research has consistently proposed that modern school science should encourage several approaches, such as active and constructivist teaching and learning, meaningful and conceptual understanding, critical thinking, and problem-solving. Inter-disciplinarity is also very important. The results of the present study highlight the importance of project-based team type work with model school students, as well as the role of the interaction between schools, society, and research institutions. The topic of nuclear energy is very suitable for such work, fitting perfectly into a contextual and interdisciplinary approach, combining knowledge of physics, chemistry, biology, mathematics, and even economics, and social and political science. Finally, cooperative learning and context-based approaches are deemed popular and relevant and consequently, contribute to scientific literacy. In this spirit, Linjse et al. (1990) have argued that information derived from the media on the radioactivity following the Chernobyl accident was particularly important as a starting point for science education topics that relate to the life-world domain. At this point, it is important to point out that traditional science education tends not to include, or even encourage, the discussion of controversial topics of importance to society, economics, and politics, such as those related to nuclear science and technologies.

The pedagogical value of the introduction of project, contextbased, teamwork in the learning process is the fact that students develop a number of skills and competencies, and in addition, they are exposed to and learn to a higher or lower degree relevant science concepts and techniques, and to the impact of science on the economy, the environment and our personal lives. The results of the present study highlight the importance of such work and the role of the connection and interaction of a modern school with scientific and research institutions. At this point, it should be stressed that despite the reference just to one model school, and despite the very small number of students, the fact that we dealt with a model school (with pupils with increased interest and preference, inclination and very good performance in the science and mathematics courses, and with highly-qualified teachers), in combination with the 
very positive findings from the assessment of the project makes us believe that the findings of this study can be generalized, certainly with a reservation.

Needless to add that, as every innovation, project type of work has certain limitations that need to be highlighted, in the hope of raising the awareness about them and the efforts at ameliorating the approach. There are two very important limiting factors: One is the carrying out of the main body of work by only a part of the participating students (a very common issue in education and educational research); the second is the often limited cognitive outcomes, especially when one has to deal with students of a wide spectrum of interests and abilities. The fact that in the present study, we had to deal with students from a model school with high abilities and commitment has certainly contributed to reducing greatly the above limitations. However, as the cognitive outcomes of this study have demonstrated, despite the encouraging performance of the model lower secondary school students in the cognitive questionnaire, especially in comparison with the performance to the same questions by $1^{\text {st }}$ year university students, there was a spreading of performances, that is, not all students had a high performance.

The limited cognitive outcomes relate with another feature of the project work: The fact that the students focus exclusively and benefit most from their own project, and very little from the other classmates' projects - in fact - it was actually in the final public seminar that students had the chance to be informed and possibly learn about the other students' projects. Teachers need to devise ways to encourage the spreading of information and knowledge about all projects among all students, for instance, by requiring each group of students to present and discuss with the whole class the main features of their project, one project at a time, so that to limit the new information presented to them each time. This is not an easy task at all, as it requires extra, and, as a rule, not available instructional time.

A final issue needs addressing. While the topic of nuclear energy is highly contextual, the question arises if it is appropriate as a topic of project work for students of such a young age, as the ninth-grade students of the present study, because of its conceptual difficulties (Nakiboĝlu and Tekin, 2006; Tsaparlis et al., 2013). Surely, good students, as those studying in model schools, must experience fewer difficulties and should be willing to meet interesting and challenging modern science concepts and topics. On the other hand, we need to be careful regarding the whole student population, while this topic must be more appropriate for older students (in the $11^{\text {th }}$ or the $12^{\text {th }}$ grade).

\section{ACKNOWLEDGMENTS}

We are grateful to all the students who participated in the project and their parents who consented that their children answer the two questionnaires. We also thank (1) professor John Kalef-Ezra of the University of Ioannina, (2) CERN researcher Antonios Papanestis, and (3) Eleni Florou of the "Democritus" NRC of Greece for their contribution to the realization of the project and their participation as speakers in the public seminar. Finally, we thank Dr. Bill Byers, who read the final version of the manuscript and made some very useful comments.

\section{REFERENCES}

Al-Balushi, S.M., \& Al-Aamri, S.S. (2014). The effect of environmental science projects on students' environmental knowledge and science attitudes. International Research in Geographical and Environmental Education, 23(3), 213-227.

Barrows, H.S. (1996). Problem-based learning in medicine and beyond: A brief overview. In: Wilkerson, L. \& Gijselaers, W.H., (Eds.), Bringing Problem-based Learning to Higher Education: Theory and Practice: New Directions for Teaching and Learning. San Francisco, CA: Jossey-Bass Publishers. p3-12.

Blumenfeld, P., Fishman, B.J., Krajcik, J., Marx, R.W., \& Soloway, E. (2000). Creating usable innovations in systemic reform: Scaling up technology-embedded project-based science in urban schools. Educational Psychologist, 35(3), 149-164.

Boyes, E., \& Stanisstreet, M. (1994), Children's ideas about radioactivity and radiation: Sources, mode of travel, uses and dangers. Research in Science and Technological Education, 12(2), 145-160.

Brislin, R.W. (1970). Back-translation for cross-cultural research. Journal of Cross-Cultural Psychology, 1(3), 185-216.

Brislin, R.W. (1986). The wording and translation of research instruments. In: Lonner, W.J., \& Berry, J.W., (Eds.), Field Methods in a Crosscultural Psychology. Newbury Park, CA: Sage Publications. p137-164.

Brown, K. (2018). The effects of a university research reactor's outreach program on students' attitudes and knowledge about nuclear radiation. Research in Science and Technological Education, 36(4), 484-498.

Calhoun, L., Shrigley, R.L., \& Showers, D.E. (1988). Designing the nuclear energy attitude scale. Science Education, 72(2), 157-174.

Cocco, S. (2006). Student Leadership Development: The Contribution of Project-based Learning. Unpublished Master's Thesis. Royal Roads University, Victoria, BC.

Cohen, L., Manion, L., \& Morrison, K. (2007). Research Methods in Education. $6^{\text {th }}$ ed. London: Routledge.

Cross, R.T., Price, R.F., Zatsepin, V., \& Gavrilenko, J.N. (1996). Lessons for science education: The print media's reporting of the Chernobyl cloud over Britain in 1986. Research in Science and Technological Education, 14(2), 125-139.

Dakabesi, D., Supiah, I., \& Luoise, Y. (2019). The effect of problem based learning model on critical thinking skills in the context of chemical reaction rate. Journal of Education and Learning, 13(3), 395-401.

Dewey, J. (2006). My pedagogic creed. In: Provenzo, E.F. Jr., (Ed.), Critical Essays in Education an Anthology of Readings. Thousand Oaks: Sage Publications. p21-30.

Dimopoulos, K., \& Koulaidis, V. (2006). School visits to a research center as a form of non formal education. International Journal of Learning, 12(10), 65-74.

Dulski, R.E., Rosalie, E.D., Raven, R.J. (1995). Attitudes toward nuclear energy: One potential path for achieving scientific literacy Science Education, 79(2), 167-187.

Durant, J., Evans, G., \& Thomas, G. (1989). The public understanding of science. Nature, 340(6228), 12-14.

Eijkelhof, H., \& Millar, R. (1988). Reading about Chernobyl: The public understanding of radiation and radioactivity. School Science Review, 70(251), 35-41.

Eijkelhof, H.M.C., Klaassen, C.W.J., Lijnse, P.L., \& Scholte, R.L.J. (1990). Perceived incidence and importance of lay-ideas on ionizing radiation: Results of a delphi-study among radiation experts. Science Education, 74(2), 183-195.

Frey, K. (1982). Die Projectmethode (The Project Method) Weinheim: Beltz.

Halkia, K. (2003). Teachers' views and attitudes towards the communication code and the rhetoric used in press science articles. In: Psillos, D., Kariotoglou, P., Hatzikraniotis, E., Tselfes, V., Fassoulopoulos, G., Kallery, M. (Eds.), Science Education in the Knowledge-based Society. Dordrecht, The Netherlands: Kluwer Academic Publishers. p415-423. 
Halkia, K., Malamitsa, K., \& Theodoridou, S. (2001). Students' Views and Attitudes Towards the Communication Code and the Rhetoric Used in Press Science Articles". Paper Presented in the $9^{\text {th }}$ European Conference for Research on Learning and Instruction. EARLI (European Association for Research on Learning and Instruction). Friburg, Switzerland.

Henriksen, E.K., \& Jorde, D. (2001). High school students' understanding of radiation and the environment: Can museums play a role? Science Education, 85(2), 189-206.

Hicks, R.W., \& Bevsek, H.M. (2011). Utilizing problem-based learning in qualitative analysis lab experiments. Journal of Chemical Education, 89(2), 254-257.

Jenkins, E.W. (1999). School science, citizenship and the public understanding of science. International Journal of Science Education, 21(7), 703-710.

Johnson, D.W., \& Johnson, R. (1991). Joining Together: Group Theory and Group Skills. $4^{\text {th }}$ ed. Englewood Cliffs, NJ: Prentice Hall.

Kaczmarek, R., Bednarek, D., \& Wong, R. (1987). Misconceptions of medical students about radiological physics. Health Physics, 52(1), 106-108.

Kendler, B.S. \& Grove, P.A. (2004), Problem-Based Learning in the biology curriculum. The American Biology Teacher, 66(5), 348-354.

Kılınç, A., Boyes, E., \& Stanisstreet, M. (2013). Exploring students' ideas about risks and benefits of nuclear power using risk perception theories. Journal of Science Education and Technology, 22(3), 252-266.

Kin, H.W.K., \& Day, J.J. (2009). A comparative study of problem-based and lecture-based learning in junior secondary school science. Research in Science Education, 39(5), 625-642.

Kokotsaki, D., Menzies, V., \& Wiggins, A. (2016). Project-based learning: A review of the literature. Improving Schools, 19(3), 267-277.

Larmer, J., Mergendoller, J., \& Boss, S. (2015). Setting the Standard for Project Based Learning: A Proven Approach to Rigorous Classroom Instruction. Alexandria, VA: ASCD and Buck Institute of Education.

Linjse, P.L., Eijkelhof, H.M.C., Klaassen, C.W.J., \& Scholte, R.L.J. (1990). Pupils' and mass-media ideas about radioactivity. International Journal of Science Education, 12(1), 67-78.

Lucas, A. (1987). Public knowledge of radiation. Biologist, 34(3), 125-129.

Markham, T. (2011). Project Based Learning. Teacher Librarian, 39(2), $38-42$.

Martins, I. (1992). Pupils' and Teachers' Understandings of Scientific Information Related to a Matter of Public Concern. (Unpublished Ph.D. Thesis University of London, Institute of Education).

Millar, R. (1994). School student's understanding of key ideas about radioactivity and ionizing radiation. Public Understanding of Science, $3(1), 53-70$.

Nakiboĝlu, C., \& Tekin, B.B. (2006). Identifying students' misconceptions about nuclear chemistry. A study of Turkish high school students. Journal of Chemical Education, 83(11), 1712-1718.

Neresini, F., Dimopoulos, K., Kallfass, M., \& Peters, H.P. (2009). Exploring a black box: Cross-national study of visit effects on visitors to large physics research centers in Europe. Science Communication, 30(4), 506-533.

Nunes, E., \& Zylbersztain, A. (1990) Goiania and Chernobyl Lesson to be Learned. Paper Presented at the $42^{\text {nd }}$ Annual Meeting of the Brazilian Society for the Progress of Science (SBPC), March.

OECD. (2015). Programme for International Student Assessment. Available from: https://www.oecd.org/pisa/pisaproducts/submission-guidelinesscience.pdf. [Last accessed on 2020 Jan 23].

Overton, T.L. \& Randles, C.A. (2015). Beyond problem-based learning: Using dynamic PBL in Chemistry. Chemistry Education Research and Practice, 16(2), 251-259.

Pease, M.A., \& Kuhn, D. (2011). Experimental analysis of the effective components of problem-based learning. Science Education, 95(1), $57-86$.

Powell, R.R., Robinson, M.G., \& Pankratius, W. (1994). Toward a global understanding of nuclear energy and radioactive waste management International Journal of Science Education, 16(3), 253-263.

Salkind, N.J. (Ed.). (2010). Encyclopedia of Research Design. Thousand Oaks, CA: Sage.

Shamos, M.H. (1995). The Myth of Scientific Literacy. New Brunswick, NJ: Rutgers University Press.

Showers, D.E. \& Shrigley, R.L. (1995). Effects of knowledge and persuasion on high-school students' attitudes toward nuclear power plants. Journal of Research in Science Teaching, 32(1), 29-43.

Szott, A. (2014). Open-ended laboratory investigations in a high school physics course: The difficulties and rewards of implementing inquirybased learning in a physics lab. The Physics Teacher, 52(1), 17-21.

Taber, K.S. (2014). Ethical considerations of chemistry education research involving "human subjects". Chemistry Education Research and Practice, 15(2), 109-113.

Tsaparlis, G., \& Gorezi, M. (2007). Addition of a project-based component to the expository physical chemistry laboratory. Journal of Chemical Education, 84(4), 668-670.

Tsaparlis, G., Hartzavalos, S., \& Nakiboğlu, C. (2013). Students' knowledge of nuclear science and its connection with civic scientific literacy in two European contexts: The case of newspaper articles. Science and Education, 22(8), 1963-1991.

Wellington, J. (1991). Newspaper science, schools science: Friends or enemies? International Journal of Science Education, 13(4), 363-372.

Yang, F.Y., \& Anderson, O.R. (2003). Senior high school students' preference and reasoning modes about nuclear energy use. International Journal of Science Education, 25(2), 221-244. 